\title{
An Analysis on Organizational Commitment and Job Satisfaction of Teachers in Private Schools Under International and Central Syllabi in Kanyakumari District of Tamilnadu
}

\author{
David Gladson Eliazer .E ${ }^{\mathbf{1}}$, Dr. P. R. Shini ${ }^{2}$ \\ ${ }^{1} \mathrm{Ph} . \mathrm{D}$ Research Scholar, Bharathiar University, Coimbatore, India \\ ${ }^{2}$ Assistant Professor of Business Administration, Sri Meenakshi Govt. Arts College for Women (A), Madurai-2, India
}

\begin{abstract}
Teachers of private schools work in an extremely competitive and challenging environment. The purpose of this study is to identify the effect of Organizational Commitment on Job Satisfaction in Private schools under international and central curriculums in Kanyakumari District of Tamil Nadu. This research paper is based on a review of academic research papers and surveys. The primary data has been collected through the help of questionnaires. Secondary data is being used to identify the commitment related problems of South Indian Educational Institutions. The three commitments have been taken as independent variables and educational sustained productivity as the dependent variable. The results indicate that Organizational Commitment is significantly related to Job Satisfaction in South Indian Private Schools. The research findings revealed that there exists positive relationship between Teachers' commitments and their Job satisfaction. The results are an indication that there is a good and strong relationship between the independent variable and the dependent variable organizational commitment. There is a large pool of employees employed by educational institutions. It is vital to maintain a committed and satisfied workforce. This paper would be of value to researchers seeking information on how commitment and sustained productivity are linked. This is an original contribution and not published anywhere else.
\end{abstract}

Keywords: Organizational Commitment (OC), Job Satisfaction (JS).

\section{Introduction}

Organizational Commitment has often been a definitive tool for the improvement of work in an organization. Many factors that enhance the organization such as productivity, employee welfare, profitability etc. have found to be the ability of the organizations to produce and keep committed employees. These employees have in turn rewarded their organization with profitability in the long run. These employees are under several influences that may or may not affect their commitment level. In this paper we will analyze the causes and effects of organizational commitment on people and how it enhances their satisfaction towards their job.

\section{Objectives of the Study}

- To find the correlation between Organizational Commitment and Job Satisfaction.

- To analyze the effect of Job Satisfaction on Organizational Commitment.

\section{Commitment}

Commitment is the act or the instance of committing, which may also be a pledge to do something pledged, especially an engagement. It is also the state of being bound emotionally (or) intellectually to a course of action (or) to another person or persons. It simply can be stated as the state or quality of being dedicated to a cause or an activity, a pledge or an undertaking. Commitment has also been identified as a continuation of a particular action which is usually a direct result of the costs associated with its termination.

\section{Organizational Commitment}

According to Meyer and Allen (1990) Organizational Commitment can be stated as the level to which an individual is involved and loyal in his organization's activities. It is the extent to which an employee is ready to put the organizations goals ahead of personal goals and self improvement. Organizational Commitment has been directly associated with attitude and behavior in the actual workplace. This statement holds true to the fact that positive or negative attitude can be directly derived from Organizational Commitment. This in turn tends to generate a coping strategy within the employee which allows for desired or undesired behavior. This is usually the end result of organizational power which tends to form a psychological map within the employees mind to tackle the given tasks while maintaining a level head. It also tends to either discourage or encourage an employee to himself engage in organizational politics. These psychological disturbances will lead to performance degradation which affects the organizational performance in the long run. When such incidents occur it becomes a question as to which level organizational politics has affected the working capability and overall attitude of an employee. ${ }^{1}$ 


\section{International Journal of Science and Research (IJSR) \\ ISSN (Online): 2319-7064}

Index Copernicus Value (2013): 6.14 | Impact Factor (2015): 6.391

\section{Organizational Commitment and Job Satisfaction}

Job satisfaction or employee satisfaction has been defined in many different ways. Some believe it is simply how content an individual is with his or her job, in other words, whether or not they like the job or individual aspects or facets of jobs, such as nature of work or supervision. Others believe it is not so simplistic as this definition suggests and instead that multidimensional psychological responses to one's job are involved. Researchers have also noted that job satisfaction measures vary in the extent to which they measure feelings about the job (affective job satisfaction). or cognitions about the job (cognitive job satisfaction).

The concept of job satisfaction has been developed in many ways by many different researchers and practitioners. One of the most widely used is "a pleasurable or positive emotional state resulting from the appraisal of one's job or job experiences". Others have defined it as simply how content an individual is with his or her job; whether he or she likes the job or not. It is assessed at both the global level or at the facet level.

In the study of organizational commitment there has been a known association between itself and job satisfaction significantly by Rohani Salleh et al. (2012). The study originated as a means to find a relation between Organizational commitment and job satisfaction. The study was performed through the analysis of demographic factors, educational factors and the position and tenure held by the particular personnel. ${ }^{2}$

Analysis was performed by the Job Development Index and Organizational Commitment Questionnaire. The study brought out facts that the salary paid to employees was discouraging and the thought of promotion also failed to satisfy. The main bulk of the work itself remained unsatisfied. The supervisors were not in position to develop or communicate and be encouraging to these employees hence the factor of commitment towards the particular organization was affected. Hence Job satisfaction remains a major antecedent for the factor of commitment.

Other studies carried out state more relations between job satisfaction and organizational commitment by Sinem Aydogdu et al. (2011). Several scales pertaining to organizational commitment and job satisfaction have been used, namely the MSQ (Minnesota Satisfaction Questionnaire). This has contributed towards identifying a specific relationship between job satisfaction and organizational commitment.

Sinem Aydogdu et al.(2011) study also suggested that there are more relations between job satisfaction and organizational commitment. Several scales pertaining to organizational commitment and job satisfaction have been used, namely the MSQ (Minnesota Satisfaction Questionnaire). This has contributed towards identifying a specific relationship between job satisfaction and organizational commitment. Positive relations have been identified between job satisfaction and all the three forms of organizational commitment. Hence job satisfaction can be identified as a major link to reveal findings regarding organizational commitment. 6

Positive relations have been identified between job satisfaction and all the three forms of organizational commitment. Hence job satisfaction can be identified as a major link to reveal findings regarding organizational commitment. ${ }^{3}$

The general consensus is that job satisfaction slightly correlated with organizational commitment. Another important revelation was a negative one between organizational commitment and higher education. Less educated employees showed a higher commitment score. Cemile Çelik (2011) has conducted a study to examine the relationship between components of Organizational commitment and job satisfaction of tax Office employees. 3 Factor analysis was conducted on the data obtained through organizational commitment scale developed by Meyer and Allen (1990). ${ }^{4}$

Mehmet Ustuner (2009) conducted a study to develop an instrument to measure organizational commitment for teachers. In order to test the criterion validity of the scale Minnesota Satisfaction Questionnaire (MSQ) and Maslach Burnout Inventory (MBI) were administered on a second group of teachers. For reliability studies, internal consistency coefficient and test-retest correlation coefficient were estimated using the relevant software. The findings from the study indicate that the 17 -item TOCS is a reliable and valid scale in terms of psychometric features. Similar studies on the validity and reliability of the scale can be repeated on other teacher groups

Job satisfaction or employee satisfaction has been defined in many different ways. Some believe it is simply how content an individual is with his or her job, in other words, whether or not they like the job or individual aspects or facets of jobs, such as nature of work or supervision. Others believe it is not so simplistic as this definition suggests and instead that multidimensional psychological responses to one's job are involved. Researchers have also noted that job satisfaction measures vary in the extent to which they measure feelings about the job (affective job satisfaction). or cognitions about the job (cognitive job satisfaction). ${ }^{5}$

Peter Lok et al. (2011) in his study "The Effect of Organizational Culture and Leadership Style on Job Satisfaction and Organizational Commitment: A cross National Comparison." investigated the relationships between employees' commitment and its various antecedents, including employees' perceptions of organizational culture, subculture, leadership style, and job satisfaction. The purpose of this study is to further clarify the relationships between commitment and the constructs discussed above, particularly organizational subculture. Hospital and Ward Culture Dimensions were measured using Wallach's (1983) Organizational Culture Index describes organizational culture in terms of three distinct dimensions: (1) Bureaucratic, (2) Innovative, and (3) Supportive. Each of the three hospital culture dimensions were measured using a six item questionnaire on a fourpoint rating scale. ${ }^{6}$ 


\section{International Journal of Science and Research (IJSR) \\ ISSN (Online): 2319-7064 \\ Index Copernicus Value (2013): 6.14 | Impact Factor (2015): 6.391}

Pattaya Pongsettakul(2008) conducted a study on ,Job satisfaction and organization commitment among professional physicians : a comparative study of physicians working in thai public and private hospitals." stating the need to compare job satisfaction factors and hospital commitment factors among doctors in public and private hospitals in Thailand. The secondary purpose was to gain a greater understanding of the relationship of job satisfaction and hospital commitment of doctors in Thailand. This research uses the questionnaires as the survey instrument. The questionnaire consists of three parts, demographic data, job satisfaction data, and organizational data. The Likert's five point scale was used to determine the answers of the respondents. $^{7}$

Caramollah Daneshfard et al. (2012) conducted a study in "Organizational commitment and job satisfaction in Islamic Azad University,". They have attempted the comparison of job satisfaction and organizational commitment in employees, managers and members of the delegation in Islamic Azad University of Kogiluyeh \& Boyer Ahmad province.

Data collection was done using the distributed questionnaires, that Meyer\& Allen's questionnaires include the 3 organizational aspects (affective, continuance and normative) to measure organizational commitment and the measurement of job satisfaction used the (MSQ) Questionnaire. The result of this study showed that the relationship between employee job satisfaction and employees organizational commitment is direct and significant.

Norazah Suki et al. (2011) have conducted a study in "Job satisfaction and organizational commitment: the effect of gender." And have examined the effect of gender on employees' perception of job satisfaction and organizational commitment. The job satisfaction instrument used in this study is a that scale consists of 15 items. A seven-point response scale was employed, Both Job Satisfaction and Organizational Commitment had a strong positive and highly insignificant influence on Gender. The results of data analysis showed that the employee's gender has no significant effect on her/his perception of job satisfaction. Both men and women have the same level of job satisfaction. $^{8}$

Sarminah Samad (2010) conducted a study in "The effects of job satisfaction on organizational commitment and job performance relationship: a case of managers in Malaysia's manufacturing companies.". They examined the relationship between organizational commitment and job performance. A self administered questionnaire was employed and distributed among senior and middle management staff of manufacturing sector specifically in electrical and electronic companies in Malaysia.

The obtained data were analyzed based on the descriptive and inferential statistics. The results revealed that there was as a positive relationship between organizational commitment and job performance. The hierarchical analysis found that job satisfaction (both the hygiene and motivating factors) played moderating role on the relationship between organizational commitment and job performance. ${ }^{9}$

Yongsun Paik et al. (2007) conducted a study in "The relationship between perceived compensation, organizational commitment and job satisfaction: the case of Mexican workers in the Korean maquiladoras." which investigated Expatriate literature and found that it has generally favored home country factors to understand expatriate success. In this study contributions were made to the field by shifting the focus to the host country workforce. The equity theory was used to examine the effects of perception gaps in compensation between host country workforce and expatriates on organizational commitment and its impact on job satisfaction and job performance. Based on field surveys and in-depth interviews of Korean expatriates as well as Mexican workers, results provide support for the hypothesis that significant perception gaps exist in compensation. The finding that compensation gap was significantly related to affective commitment only is of crucial importance. Results also suggest that only affective commitment is positively related to job satisfaction and performance. $^{10}$

\section{Research Design}

The research design in this study is used to examine the effects of Teacher commitment on Job satisfaction in private schools of Kanyakumari District of Tamil Nadu. The data collected for testing was taken from primary sources. The data was collected through questionnaires from a sample of 50 Teachers of private schools in Kanyakumari district with international curriculum and central curriculum (Delhi \& Cambridge) to identify the effect of commitment on job satisfaction. The questionnaire contained 10 items which help in identifying the impact of commitment on job satisfaction. The secondary data was collected from books, magazines, research papers, internet, annual reports etc.

\section{Analysis and Interpretation}

\section{Measurement}

The questionnaire consists of 25 items in which 10 items were based from Organizational Commitment Questionnaire by Allen \& Meyer. Samples were taken for organizational commitment and its underlying factors that influence job satisfaction. The model has been tested with reliability analysis and has returned a Cronbach's alpha of .676. Hence the current model being used is of acceptable reliability. 10 questions pertaining to job satisfaction were also used. All These questions were measured on a 5 point Likert scale ranging from

- Highly Agree (5)

- Agree(4)

- Neutral (3)

- Disagree(2)

- Strongly Disagree (1)

In this research paper correlation was used to test the relation between organizational commitment and job satisfaction and regression was used to test the nature of the relation between dependence of variables. 


\section{International Journal of Science and Research (IJSR) \\ ISSN (Online): 2319-7064 \\ Index Copernicus Value (2013): 6.14 | Impact Factor (2015): 6.391}

\section{Hypothesis}

1) There is a significant correlation between Organizational Commitment and Job Satisfaction of Employees.

2) Organizational Commitment depends on the Job Satisfaction of Teachers in Private Schools of Kanyakumari District of Tamil Nadu.

Table 1: Scores of the respondents

\begin{tabular}{|c|c|c|}
\hline Particulars & $\begin{array}{c}\text { Organizational } \\
\text { Commitment }\end{array}$ & $\begin{array}{c}\text { Job } \\
\text { Satisfaction }\end{array}$ \\
\hline Sum of scores & 1843 & 1865 \\
\hline Number of respondents & 50 & 50 \\
\hline Mean & 36.86 & 37.3 \\
\hline Standard Deviation & 7.22 & 7.87 \\
\hline Mean + Standard Deviation & 44.08 & 45.17 \\
\hline Mean - Standard Deviation & 29.64 & 29.43 \\
\hline Low level & $<29$ & $<29$ \\
\hline Medium level & $29-44$ & $29-45$ \\
\hline High level & $>44$ & $>45$ \\
\hline
\end{tabular}

Source: Survey Data

Table - 1 shows that the Organizational Commitment score of respondents greater than 44 (Mean + Standard Deviation)is considered as respondents perceived a high level of Organizational Commitment, below 29(Mean Standard Deviation)are considered as respondents perceived low level of Organizational Commitment and the score of respondents lying between 29 to 44 is considered as medium level of Organizational Commitment. Likewise the Job Satisfaction score of respondents greater than 45 (Mean + Standard Deviation)is considered as respondents with high level of Job Satisfaction, below 29 (Mean - Standard Deviation)are considered as respondents with low level of Job Satisfaction and the score of respondents lying between 29 to 45 is considered as having medium level of Job Satisfaction. Table 2 shows the classification of respondents on the basis of their Organizational Commitment.
Table 2: Classification of the Respondents Based on Organizational Commitment Level

\begin{tabular}{|c|l|c|c|}
\hline $\begin{array}{c}\text { Sl. } \\
\text { No. }\end{array}$ & $\begin{array}{l}\text { Organizational } \\
\text { Commitment }\end{array}$ & $\begin{array}{l}\text { Number of } \\
\text { respondents }\end{array}$ & Percentage \\
\hline 1 & Low & 0 & 0 \\
\hline 2 & Medium & 27 & 54 \\
\hline 3 & High & 23 & 46 \\
\hline \multicolumn{2}{|c|}{ Total } & 50 & 100 \\
\hline
\end{tabular}

Source: Survey data

It is clear from Table - 2 that none of the respondents have a low level of Organizational Commitment, while 27(54\%) respondents have a medium level of Organizational Commitment and 23(46\%) respondents have a high level of organizational commitment. Table-3 shows classification of respondents on the basis of their Job Satisfaction.

Table 3: Classification of the Respondents Based on Job Satisfaction

\begin{tabular}{|c|l|c|c|}
\hline S. No. & Job Satisfaction & Number of respondents & Percentage \\
\hline 1 & Low & 2 & 4 \\
\hline 2 & Medium & 24 & 48 \\
\hline 3 & High & 24 & 48 \\
\hline \multicolumn{2}{|c|}{ Total } & 50 & 100 \\
\hline
\end{tabular}

Source: Survey data

Table-3 reveals that 2(4\%) respondents have a low level of Job Satisfaction, while 24(48\%) respondents have a medium level of Job Satisfaction and 24(48\%) respondents have a high level of Job Satisfaction.

\section{Relation Between Organizational Commitment and Job Satisfaction}

To determine if there is any relation between the Organizational Commitment and Job Satisfaction experienced by the respondents, Organizational Commitment is cross tabulated with the level of Job Satisfaction. Table -4 shows the results of cross tabulation of organizational commitment and Job Satisfaction.

Table 4: Organizational Commitment and Job Satisfaction of Respondents

\begin{tabular}{|c|c|c|c|c|c|c|c|c|c|}
\hline \multirow{3}{*}{ Sl. No. } & \multirow{2}{*}{$\begin{array}{c}\text { Organizational } \\
\text { Commitment }\end{array}$} & \multicolumn{9}{|c|}{ Job Satisfaction } & \multicolumn{2}{c|}{ High } & \multicolumn{2}{c|}{ Total } \\
\cline { 3 - 11 } & & \multicolumn{2}{|c|}{ Low } & \multicolumn{2}{c|}{ Medium } & No. & $\mathbf{\%}$ & No. & \% \\
\hline & Low & 0 & 0 & 0 & 0 & 0 & 0 & 0 & 0 \\
\hline 1 & Medium & 4 & 8 & 17 & 34 & 5 & 10 & 26 & 52 \\
\hline 3 & High & 0 & 0 & 5 & 10 & 19 & 38 & 24 & 48 \\
\hline Total & & 4 & 8 & 22 & 44 & 24 & 48 & 50 & 100 \\
\hline
\end{tabular}

Source: Survey data

Table - 4 shows that the6 percent of respondents with low level of organizational commitment have a low level of Job Satisfaction and4 percent of respondents with low level of organizational commitment have a medium level of Job Satisfaction.34 percent of respondents with medium level of organizational commitment have a low level of Job Satisfaction, 28 percent of respondents with medium level of organizational commitment have a medium level of Job Satisfaction and 6 percent of respondents with medium level of organizational commitment have a high level of Job Satisfaction. 4 percent of respondents with high level of organizational commitment have a low level of Job
Satisfaction, 10 percent of respondents with high level of organizational commitment have a medium level of Job Satisfaction and 8 percent of respondents with high level of organizational commitment have a high level of Job Satisfaction.

Correlation analysis is used to test the first hypothesis "There is a significant correlation between Organizational Commitment and Job Satisfactions of Employees" and to measure the degree of association between the two sets of qualitative data. Table - 5 shows the correlation between Organizational Commitment and Job Satisfaction of respondents. 


\section{International Journal of Science and Research (IJSR) \\ ISSN (Online): 2319-7064 \\ Index Copernicus Value (2013): 6.14 | Impact Factor (2015): 6.391}

Table 5: Correlation between Organizational Commitment and Job Satisfaction

\begin{tabular}{|c|c|c|c|c|}
\hline & Mean & $\begin{array}{c}\text { Standard } \\
\text { deviation }\end{array}$ & $\begin{array}{c}\text { Organizational } \\
\text { Commitment }\end{array}$ & $\begin{array}{c}\text { Turnover } \\
\text { Intention }\end{array}$ \\
\hline $\begin{array}{c}\text { Organizational } \\
\text { Commitment }\end{array}$ & 36.86 & 6.15 & 1.000 & $.802^{* *}$ \\
\hline Job Satisfaction & 37.30 & 7.87 & $.802^{* *}$ & 1.000 \\
\hline
\end{tabular}

The result of the Correlation analysis reveals that the two variables, namely, Organizational Commitment and Job Satisfaction are positively correlated. Though there is a positive correlation, the Correlation coefficient (0.802) show the significance is low. Hence the first hypothesis of the study, there is a correlation between the Organizational Commitment and Job Satisfaction of the employees is accepted.

Regression analysis is applied to test the second hypothesis "Organizational Commitment depends on the Job Satisfaction of Grade Teachers in Private Schools". It explains the variation in one variable (Organizational Commitment- Y), based on the variation in other variable (Job Satisfaction- X). The ANOVA table pertaining to the testing of significance for this regression is given in Table 6 .

Table 6: ANOVA for testing Regression of Organizational Commitment and Job Satisfaction

\begin{tabular}{|l|c|c|c|c|c|c|}
\hline & $\begin{array}{c}\text { Sum of } \\
\text { Squares }\end{array}$ & $d f$ & $\begin{array}{c}\text { Mean } \\
\text { Square }\end{array}$ & $F$ & $R^{2}$ & Sig. \\
\hline Regression & 371.88 & 1 & 1191.816 & 86.651 & .644 & .000 \\
Residual & 2180.14 & 48 & 13.754 & & & \\
Total & 2552.02 & 49 & & & & \\
\hline \multicolumn{7}{|c|}{ Coefficients } \\
\hline Constant & & & 13.476 & \\
Job Satisfaction & & & .802 & \\
\hline
\end{tabular}

$\mathrm{R}^{2}$ is a measure of the percent variation explained by the independent variable (Job Satisfaction) on the dependent variable (Organizational Commitment). An $\mathrm{R}^{2}$ value of 0.644 indicates that $64.4 \%$ of the variance in Organizational Commitment is accounted for by Job Satisfaction and its square. The regression equation of Job Satisfaction on Organizational Commitment is constructed as follows:

$$
\mathrm{Y}=13.476-0.802 \mathrm{X}
$$

From the ANOVA table there is a slight effect of Organizational Commitment on the Job Satisfaction score of respondents. Hence, it is concluded that the second hypothesis the level of Job Satisfaction depends on the Organizational Commitment of Teachers in Private Schools is accepted.

\section{Discussion}

The study reveals that there exists a correlation between organizational commitment and job satisfaction. In majority of the cases the alternative hypothesis stating a positive relation has been accepted and the null hypothesis rejected. Hence there exists a positive relationship between organizational commitment and job satisfaction. Hence it should be noted that the management of private schools must continue on improving the teachers' commitment by maintaining an excellent atmosphere that is challenging, beneficial and trustworthy.

\section{Conclusion}

This study analyzed the link between organizational commitment and job satisfaction in private schools of Kanyakumari District of Tamil Nadu, India. Questions were based on Organizational Commitment Questionnaire by Meyer and Allen. In private schools job satisfaction is a positively affecting the organizational commitment

\section{References}

[1] John .P Meyer, Natalie .J Allen "A three component conceptualization of organizational commitment. ", Human Resource Management Review,Vol 1.,No.1, p 61-89,1990.

[2] Rohani Salleh, Mishaliny Sivadahasan Nair, Haryanni Harun, "Job Satisfaction, Organizational Commitment and Turnover Intention: A case study on employees of a retail company in Malaysia" World Academy of Science, Engineering and Technology International Journal of Social, Management, Economics and Business Engineering, Vol.6 ,No.12, p 702-709, 2012.

[3] Sinem Aydogdu, Baris Asikgil and Mimas Sinan, "An Empirical study of the relationship among Job Satisfaction, Organizational Commitment and Turnover Intention.”, International Review of Management and Marketing,Vol.1, No.3, p.43-53, 2011.

[4] Cemile Celik (2012) "Relationship of organizational commitment and job satisfaction: a field study of tax office employees." ??

[5] Mehmet Ustuner "Teachers" Organizational Commitment Scale: A Validity and Reliability Study.", Inonu University Journal of the faculty of education, No.1, Vol.10, p 1-17, 2008.

[6] Peter Lok, John Crawford, "The Effect of Organizational Culture and Leadership Style on Job Satisfaction and Organizational Commitment: A cross National Comparison.", Journal of Management Development, Vol.23,No.4, p321-338, 2004.

[7] Pattaya Pongsettakul ,"Job satisfaction and organization commitment among professional physicians : a comparative study of physicians working in thai public and private hospitals.",RU International Journal, Vol.2,No.2, p41-52,2008.

[8] Norazad M. Suki and Norbayah M. Suki ,"Job satisfaction and organizational commitment: the effect of gender.", International Journal of Psychology Research, Vol.6, No.5, p1-p15, 2011.

[9] Sarminah Samad, "The effects of job satisfaction on organizational commitment and job performance relationship: a case of managers in Malaysia's manufacturing companies.", European Journal of Social Sciences, Vol.18, No.4, p.602-611, 2011.

[10] Youngsun Paik, K. P. Parboteeah, W. Shim, "The relationship between perceived compensation, organizational commitment and job satisfaction: the case of mexican workers in the korean maquiladoras.", International Journal of Human Resource Management, Vol.18, No.10, p.1768-1781, 2007.

\section{Volume 5 Issue 4, April 2016

